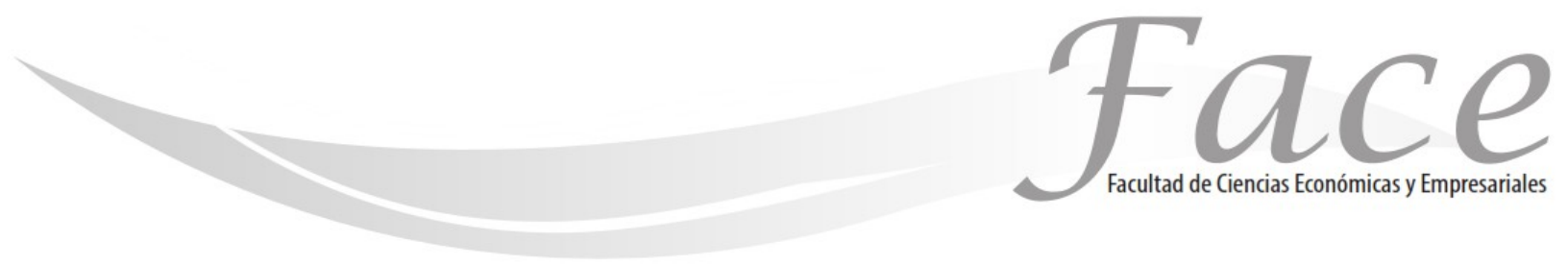

ISSN Impreso: 1794-9920

ISSN Electrónico: 2500-9338

Volumen $17-\mathrm{N}^{\circ} 2$

Año 2017

Págs. $120-129$

\title{
LAS TASAS DE INTERÉS EN LAS VENTAS A CRÉDITO EN PAMPLONA, UN NEGOCIO DE USURA*
}

\author{
Juan Manuel Villamizar Ramírez * \\ Enlace ORCID: http://orcid.org/0000-00027733-0927 \\ Ruth Mayerly Guerrero Jaimes *** \\ Enlace ORCID: http://orcid.org/0000-0002-2179-7691
}

Fecha de Recepción: 30 noviembre 2016

Fecha de Aprobación:2 febrero 2017

\section{Resumen:}

El propósito de esta investigación fue determinar las tasas de interés que las empresas comerciales del municipio de Pamplona que venden muebles y electrodomésticos a crédito, cobran a sus clientes a la hora de realizar sus compras y compararlas con las permitidas por la ley. Según el Banco de la Republica (2013), la importancia del crédito para una economía es muy grande. Gracias al crédito, las personas, las empresas y los Estados pueden tener acceso a recursos que, de otra forma, serían difíciles de obtener. De igual forma las ventas a crédito son un fenómeno que ha venido creciendo en los últimos años en Colombia (Revista Dinero, 2017). Este fenómeno también tocó la población objeto de estudio Pamplona, Norte de Santander. Se adelantó un estudio de corte descriptivo, con una muestra de los $60 \%$ de las empresas del ramo, oficialmente inscritas en la Cámara de Comercio del municipio. Surgieron datos importantes que permitieron concluir que los comerciantes del Municipio de Pamplona dedicados a la compra y venta de electrodomésticos cobran por las transacciones a crédito, tasas por encima de la permitida por la ley. También se consideró que se debe estudiar varias alternativas antes de realizar una compra, que puede resultar menos costosa..

Palabras Claves: Tasas de interés, Ventas a crédito, Tasa de usura, Anualidades

** Contador Público. - Especialista y Magister en Finanzas- Docente Universidad de Pamplona Correo electrónico: juanmvillamizar@hotmail.com, juanmanuel@unipamplona.edu.co

*** Contador Público- Magíster en Ciencias Contables- Docente Universidad de Pamplona- Correo electrónico: ruthjaimesguerrero@hotmail.com, ruthguerrero@unipamplona.edu.co 


\title{
INTEREST RATES ON CREDIT SALES IN PAMPLONA, A USED BUSINESS
}

\begin{abstract}
The purpose of this investigation was to determine the interest rates that the commercial companies of the municipality of Pamplona that sell furniture and appliances on credit, charge their customers when making their purchases and compare them with those allowed by law. According to the Bank of the Republic (2013), the importance of credit for an economy is very large. With credit, individuals, businesses and States can access resources that would otherwise be difficult to obtain. Similarly, credit sales are a phenomenon that has been growing in recent years in Colombia (Revista Dinero, 2017). This phenomenon also affected the study population of Pamplona, Norte de Santander. A descriptive study was carried out, with a sample of $60 \%$ of the companies in the sector, officially registered in the Chamber of Commerce of the municipality. Important data emerged that allowed to conclude that the merchants of the Municipality of Pamplona dedicated to the purchase and sale of electrical appliances charge for transactions on credit, rates above that allowed by law. It was also considered that several alternatives should be studied before making a purchase, which may be less costly.
\end{abstract}

Keywords: Interest rates, Credit sales, Usury rate, Annuities

\section{LAS TASAS DE INTERÉS EN LAS VENTAS A CRÉDITO EN PAMPLONA, UN NEGOCIO DE USURA*}

\section{Resumo}

O objetivo desta pesquisa foi determinar as taxas de juros que as empresas comerciais no município de Pamplona que vendem móveis e eletrodomésticos a crédito, cobram aos seus clientes ao fazer compras e compará-los com aqueles permitidos por lei. De acordo com o Banco de la Republica (2013), a importância do crédito para uma economia é muito grande. Graças ao crédito, os indivíduos, empresas e Estados podem ter acesso a recursos que de outra forma seriam difíceis de obter. Da mesma forma as vendas a crédito são um fenómeno que

tem vindo a crescer nos últimos anos na Colômbia (Money Magazine, 2017). Este fenômeno também atingiu a população-alvo de Pamplona, estudo Norte de Santander. Um estudo descritivo foi à frente cortado com uma amostra de $60 \%$ das empresas do setor, oficialmente registrada na Câmara de Comércio Township. Surgiu dados importantes que permitiu que os comerciantes a concluir que a Câmara Municipal de Pamplona dedicada à compra e venda de carga elétrica para condições de crédito, acima das taxas permitidas por lei. Considerou-se também a ser estudado várias alternativas antes de fazer uma compra, o que pode ser menos caro.

Palavras-chave: taxas de juros, vendas de crédito, taxa de usura, anuidades 


\section{INTRODUCCIÓN:}

El dinero ha sido uno de los ejes que ha movido la economía desde los tiempos de la edad media, fundamental en todas las actividades económicas; a través de él ha crecido la economía al permitir el intercambio de productos, lo que generó el desarrollo del comercio de todas las maneras posibles, por esta razón constituye una variable para promover el desarrollo de la economía local o nacional. Reina et at, (2006) plantea que el dinero está presente en muchas de las actividades que realizamos diariamente. Usamos dinero para pagar lo que compramos y para poder hacer cosas cotidianas como transportarnos, ir al médico o ir a cine. Es difícil pensar que transcurra un día normal en el que realicemos nuestras actividades corrientes sin que el dinero esté presente.

Así mismo, el dinero según Palermo (2016) es un recurso de intercambio en nuestra sociedad que nos permite adquirir víveres y ropa, casa y transporte. Se convirtió en una manifestación de seguridad para muchas personas por consiguiente, no es difícil de entender que sea el recurso más buscado. Por esta razón muchas personas en la sociedad presentan necesidades que solventan mediante la adquisición de productos y servicios para lo cual ejercen una transacción comercial, que puede realizar a través de una transacción en efectivo 0 acredito.

La realidad del mercado es que la débil capitalización de las empresas y las dificultades que tienen para obtener financiación, les lleva a diversificar sus fuentes de recursos financieros y a buscar financiación extra bancaria sin costo. Esta fuente de financiación no es otra que la otorgada por los suministradores a sus compradores a través de los aplazamientos de pago, de manera práctica que el proveedor actúa como prestamista y el cliente como prestatario. El crédito comercial que conceden los proveedores constituye la principal fuente espontánea de financiación que disponen las empresas y es uno de los medios más flexibles de financiación a corto plazo. Rating Empresarial (2011)

Igualmente, El Banco de la Republica (2013), argumenta que "Ante la necesidad de recursos (dinero) por parte de las personas, las familias las organizaciones y proyectos, las entidades financieras han desarrollado diferentes tipos de herramientas que permiten la obtención de dichos recursos, la herramienta más común es el crédito. La importancia del crédito para una economía es muy grande. Gracias al crédito, las personas, las empresas y los gobiernos pueden tener acceso a recursos que, de otra forma serían difíciles de obtener"

El crédito establece una relación de confianza que como tal naturalmente tiene sólo importancia potencial y se transforma en un fenómeno dinámico sólo en el momento que el crédito se activa en una forma de movimiento de capital; por lo anterior, al investigar lo que significa "confianza" en la operación crediticia, se reconoce el ofrecimiento de una garantía de que el tomador del crédito cumplirá con sus obligaciones resultantes de la operación de crédito y que, por consiguiente, el dador de crédito no sufrirá pérdidas. Soto, (2009).

El crédito se ha convertido a nivel mundial en un tema muy importante como lo manifiesta el Banco de la Republica (2015), dejando ver la importancia del crédito para una economía es trascendental. Constituye el medio efectivo con el que las personas, las empresas y los Estados pueden tener acceso a recursos en el momento dado para satisfacer necesidades. Los créditos pueden incentivar el consumo de las personas y, de esta forma, activar el sistema productivo del país. Las empresas, gracias a los créditos, pueden realizar proyectos e inversiones que les permitan mejorar su producción y sus ingresos, que, a la postre, también son ingresos para el país. Al Estado, los créditos le permiten llevar a cabo inversión social, en infraestructura y en otros propósitos para mantener la actividad económica del país en niveles aceptables 0 favorables.

Sin embargo, el nivel de endeudamiento (los créditos) debe mantenerse en niveles aceptables, de tal suerte que no se afecte la estabilidad económica de las personas, las empresas, las organizaciones y del país en general. En un medio donde la tendencia es la economía de consumo es cada día más alta, las personas tienden a incurrir en ellos. En los últimos años se ha registrado un crecimiento significativo del gasto de los colombianos en bienes de consumo. Desde el 2007, el incremento anual promedio de este concepto supera el 40 por ciento, y entre los años 2002 y 2006 el descenso de las tasas de interés y la recuperación de la economía dieron lugar a un escenario ideal para el aumento del endeudamiento de los hogares. Más que hablar de una buena inversión, en materia de bienes de consumo se debe hablar de oportunidad. Portafolio (2008). Otra variable de gran impacto en las finanzas personales.

Así mismo, es importante considerar la tasa de interés que le cobran por estos bienes de consumo: Cuando no tenemos la totalidad del dinero para comprar un vehículo, un electrodoméstico, ropa, elementos deportivos, muebles, etc., es válido que el mismo vendedor nos facilite adquirir el producto y pagarlo en cuotas, cobrando un interés por dicho plazo y se deben seguir unas recomendaciones. Actualícese (2011). Por otra parte, como variable importante es la financiación aparecen las ventas a crédito, vista como un estrategia comercial de uso frecuente en las sociedad, no sólo impulsa negocios de bienes durables 
como carros, sino que igualmente permite a los consumidores comprar, sus electrodomésticos, con mayor facilidad.

Desde este contexto, a nivel regional, se estudió a la ciudad de Pamplona que es una población de 57.803 habitantes donde las actividades económicas se centran principalmente en el comercio, especialmente ventas de electrodomésticos, ropa calzado, servicios, permitiendo inferir que este fenómeno es habitual entre los habitantes. Se centró el estudio en el sector comercial que venden electrodomésticos a crédito, este sector representa un alto porcentaje de ingresos para los comerciantes, por tanto, fue importante analizar allí este comportamiento socioeconómico de la población y así poder establecer en estas ventas a crédito, cuál es la tasa cobrada y si está por debajo de la tasa permitida por la ley. Desde este contexto, se propuso para analizar las tasas de interés en las ventas a crédito en el municipio de Pamplona, un estudio descriptivo con un enfoque cuantitativo, del cual se tomó una muestra correspondiente al $60 \%$ del total de las empresas formalmente registradas en Cámara de Comercio de Pamplona, empresas del ramo que venden a crédito específicamente en el sector de muebles y electrodomésticos.

Desde esta perspectiva, la fiebre del consumo, impulsada por ventas de electrodomésticos a crédito en los últimos años ha generado un repunte en la economía sobre los créditos de consumo y línea marrón. "La compra de televisores, neveras o computadores se mantiene disparada, en muchos casos a través del crédito. Aunque el aumento de las tasas de interés lo ha frenado" Portafolio (2007). Así mismo, este tipo de compras es muy utilizado por familias de estratos bajos por la facilidad para acceder a ellos. El crédito y las tasas de interés se vienen convirtiendo en un fenómeno que está causando mayor endeudamiento por parte de las familias y en la mayoría de los casos sin conocer claramente cuál es la tasa de interés cobrada.

El artículo presenta algunas conclusiones como resultado del estudio que evidencian el manejo y uso del crédito por parte de la mayoría de las empresas comerciales del municipio de Pamplona dedicadas a vender bajo esta modalidad, muebles y electrodomésticos y qué tan congruentes son las tasas de interés que cobran con las disposiciones de Ley. Para una mejor comprensión del tema en este artículo se abordó desde el concepto y tipo de interés, la usura, la informalidad en los créditos, la inflación y finalmente maneras de realizar un crédito comercial, que utilizado inteligentemente puede ser una buena alternativa para adquirir un bien.

\section{Concepciones sobre el crédito}

Al hablar del dinero, es importante hacer referencia al crédito, de acuerdo a su definición: El crédito es un préstamo de dinero a una persona o entidad, que se compromete a devolverlo en un solo pago o en forma gradual (en un cierto plazo, mediante un pago de cuotas). Habitualmente se pacta un interés que compensa al dador del crédito por el tiempo que no dispondrá de ese dinero para utilizarlo para otros fines. Meza (2008).

Como define la Enciclopedia de Economía (2009) el término De credere, confiar, el termino crédito se utiliza en el mundo de los negocios como sinónimo de préstamos 0 endeudamiento.

Una operación crediticia consiste en la trasferencia 0 cesión temporal del acreedor al deudor de un derecho de propiedad del primero sobre un determinado bien (generalmente dinero) para que el segundo disponga de él de la manera que más le convenga por un tiempo determinado, al tiempo del cual habrá de devolverlo al deudor junto con sus intereses.

También es importante mencionar que "El acceso al crédito y al aseguramiento de las actividades comerciales internacionales son factores determinantes del funcionamiento de la economía global. El crédito al comercio es distinto de otras formas de crédito, dado que incorpora un mayor nivel de riesgo derivado del componente internacional de las operaciones que atiende. La financiación al comercio puede adoptar diversas formas en función del nivel de confianza entre las partes y de la implicación en ella de los agentes de la actividad comercial 0 de intermediarios financieros. Montes, (2010).

\section{El Interés}

Meza (2008, Pág. 28) al analizar el concepto del valor del dinero en el tiempo se llega a la conclusión de que su uso, no puede ser gratuito. Si se acepta la opción de recibir 1.000.000 dentro de un año a no recibirlos en el día de hoy, se admite que se use este dinero y, por tal razón, se debe reconocer una cantidad adicional que se llama valor del dinero en el tiempo. La medida de ese incremento del dinero en un tiempo determinado se llama interés., es decir que el interés es la manifestación del valor del dinero en el tiempo.

El interés está ligado al concepto del capital, el tiempo y el riesgo. Puede decirse que es la compensación que el dueño del capital recibe de parte de quien usa los fondos. Esta compensación puede adoptar diversos nombres según la naturaleza del bien capital: Alquiler o renta, dividendo, flete e interés, este último aplicado a los capitales monetarios, etc. Saint-hilaire (2010) 
Por otra parte, cuando se habla del crédito también es importante mencionar los tipos de interés existentes. Existen diferentes tipos de interés, como lo define Santa cruz (2013) dentro de los conceptos fundamentales existentes en la ciencia económica, uno de ellos es el concepto de tipo de interés. Las distintas escuelas de pensamiento económico han dado diferentes visiones de qué es el tipo de interés, cómo se aplica y cuáles son sus fundamentos. Sin embargo, prevalecen dos clases de tipos de interés: el tipo de interés real y el tipo de interés nominal. El interés real se determina por los bienes y servicios del mundo (edificios, coches, producción agrícola, entre otros. En cambio, el tipo de interés nominal es el precio al que se compra y vende dinero en un mercado. En este sentido, el autor hace referencia a los tipos y tasas de interés, que finalmente es con la que se pacta la realización de un crédito.

\section{Tasa de Interés}

Según el Banco de la República (2013), la tasa de interés es el precio del dinero en el mercado financiero. Al igual que el precio de cualquier producto, cuando hay más dinero la tasa baja y cuando hay escasez sube. Cuando la tasa de interés sube, los demandantes desean comprar menos, es decir, solicitan menos recursos en préstamo a los intermediarios financieros, mientras que los oferentes buscan colocar más recursos (en cuentas de ahorros, CDT, etc.). Lo contrario sucede cuando baja la tasa: los demandantes del mercado financiero solicitan más créditos, y los oferentes retiran sus ahorros. No es común, cuando se realiza una operación financiera, expresar el valor de los intereses recibidos en cifras monetarias, si no que se utiliza un indicador expresado como porcentaje que mide el valor de los intereses, llamado tasa de interés. La palabra tasa se deriva del verbo tasar que significa medir. Como ecuación matemática la tasa de interés (i) es la relación entre lo que se recibe de intereses (I) y la cantidad prestada o invertida ( P). Meza (2008, pág. 29). Igualmente para una mejor comprensión del tema investigado se presentan los siguientes conceptos de tasas. Tal como lo plantea Meza (2008, pág. 29)

- $\quad$ Tasa de interés: Es lo que se paga o se cobra por usar el dinero de otros.

- $\quad$ Tasa Nominal Anual: es aquella tasa que esta expresada en años acompañada de la palabra capitalizable que significa el número de veces que gana interés en el año; la tasa nominal anual es una tasa aparente porque no refleja la realidad. otras palabras es la tasa nominal anual dividida entre el número de periodos que tiene el año que se capitaliza el interés.

- Tasa efectiva anual: es la verdadera tasa que se cobran o la verdadera tasa que se pagan.
- $\quad$ Tasa efectiva periódica: es la tasa que se calcula para cualquier problema de matemáticas financieras (y es la tasa que se calculó en esta investigación).

- $\quad$ Tasa de Usura: Es la tasa máxima permitida por la ley, en Colombia la tasa máxima de usura para el primer trimestre del 2016 es del $29.52 \%$, equivalente a efectiva anual, equivalente a tasa nominal del $26.15 \%$ y a una tasa efectiva periódica mensual del $2.18 \%$. Superfinanciera. (2016).

\section{Sustentos teóricos sobre la inflación}

La inflación, este fenómeno económico hace que el dinero día a día pierda poder adquisitivo, es decir que el dinero se desvalorice. En una economía de mercado, es decir, en las cual los precios se establecen en el libre juego de la oferta y las demandas de bienes y servicios, estos no tienen una variación estable. Por el contrario tienden a desbordarse, especialmente en las economías subdesarrolladas, en las cuales hay dificultad para el abastecimiento de productos 0 bajos niveles de eficiencia en la producción. Meza (2008, pág. 26).

Igualmente, en economía la inflación es el aumento sostenido y generalizado del nivel de precios de bienes y servicios, medido frente a un poder adquisitivo estable. Se define también como la caída en el valor de mercado o del poder adquisitivo de una moneda en una economía en particular, lo que se diferencia de la devaluación, dado que esta última se refiere a la caída en el valor de la moneda de un país en relación con otra moneda cotizada en los mercados internacionales, como el dólar estadounidense, el euro 0 el yen. Es un desequilibrio económico caracterizado por la subida general de los precios y provocado por la excesiva emisión de billetes de banco, un déficit presupuestario o por falta de adecuación entre la oferta y la demanda. Vargas (2008).

Así mismo el autor manifiesta que la inflación es la presencia en la circulación de una gran cantidad de papel moneda que rebasa las necesidades de la circulación de mercancías o que sobrepasa a la cantidad de oro que lo respalda. La inflación se puede dar porque el Estado financia su gasto público a través de la creación (emisión de dinero, que al no tener respaldo pierde valor y por lo tanto disminuye su poder adquisitivo de la gente, se tiene que pagar más dinero por las mismas cosas. Se rompe el equilibrio para que la producción circule normalmente, hay un exceso de circulante en relación con la producción.

El concepto de usura y su aplicación en Colombia.

La práctica de la usura es tan vieja como el hombre, aunque en menos de dos siglos, la usura pasó de ser un delito condenado absolutamente desde los tiempos más antiguos, castigado severamente por la ley y despreciado 
por todo el mundo, a ser considerada como una forma reconocida y honorable de hacer negocios, cuyos practicantes recibían los más altos honores que un Estado puede otorgar. Breviarios (2017).

La usura representa el cobro excesivo de intereses en un préstamo que otorgue una persona u organización a la cual se le llamaría usurero. Al realizar un préstamo o un crédito, esté tendrá unas condiciones bajo las cuales ha de ser pagado. Condiciones pueden ser el tiempo en que debe ser retornado el valor total del préstamo, la forma y periodos en los que éste debe ser retornado, y el costo que, por tomarlo, asume la persona a quien se le otorga, costo que generalmente está determinado por una tasa de interés.

Igualmente, los intereses que se cobran en los préstamos o créditos, tienen incorporada dentro de ellos la teoría de que ha de haber un precio justo y razonable a la hora de cobrarlos y que, por lo tanto, no se determinan exclusivamente con base en la oferta y la demanda de los créditos; es esta la razón de que los gobiernos de algunos países hayan establecido un límite máximo para el cobro de intereses en los préstamos, límite que recibe el nombre de tasa de usura. Esta tasa, si no es adecuada, puede propiciar el desarrollo de mercados no legales para los préstamos, sin embargo, su función principal es la de evitar que se cobren intereses muy altos a todas aquellas personas que soliciten créditos o préstamos. Banco de la republica (2016)

Según la definición de usura, es el al acto o a la acción mediante la cual un individuo o una entidad obtienen ganancias a partir del altísimo cobro de intereses sobre un préstamo o sobre casi cualquier tipo de transacción bancaria, comercial o financiera. La usura es un fenómeno que permite enriquecerse en gran modo a aquel que lo lleve a cabo pero que significa un claro y profundo empobrecimiento para quien debe pagar los intereses ya que los mismos son incontrolables y pueden terminar siendo incluso mucho más elevados que el préstamo pedido en una primera instancia. Enciclopedia de Economía (2009)

Hablar de la usura no se puede negar que en Colombia es un tema que está latente dentro de la economía informal, ya que la realidad de muchos comerciantes y personas del común tienen negada la posibilidad de acceder a un crédito comercial o bancario, lo que los termina obligando a acudir a los famosos "gota a gota" donde terminan pagando intereses del $10 \%$ en muchas ocasiones diario, teniendo en cuenta las apreciaciones anteriormente presentadas de lo que está permitido dentro de la legalidad, esto sería considerado como delito.
La informalidad en los créditos

La informalidad es un problema que se debe analizar por parte del Gobierno y el sector bancario, Asobancaria, (2015), Colombia es el segundo país de Latinoamérica con mayor porcentaje de personas con créditos informales, con $6,45 \%$, sólo superado por Panamá con una cifra de $10,04 \%$. De igual forma si se miran los datos de financiación a través de familiares o amigos, la cifra es de $18,27 \%$, lo que evidencia el largo camino que queda por recorrer para que el crédito se haga de manera formal, el cual tan solo $11,95 \%$ de la población lo utiliza. La alta cifra se explica porque siguen existiendo barreras al acceso, por una parte, la tasa de usura hace que no se pueda atender a personas a una tasa más alta de la permitida, y debido a la regulación en cuanto a la documentación, ya que se pide certificado laboral sin tener en cuenta que más de la mitad de los trabajadores son informales.

De acuerdo a estas estadísticas, los bancos en Colombia actualmente han adquirido el compromiso de ofrecer nuevos productos y servicios financieros, que sean de fácil acceso a las poblaciones que aún no han tenido ninguna conexión con la banca. Esto ha llevado a las entidades bancarias a realizar varios estudios que faciliten la posibilidad de formalizar la economía de las personas, que actualmente se encuentran dentro de $55 \%$ que acuden a préstamos no formales (ilegales, no bancarios, etc.), por no cumplir con ciertos requisitos que exige el sector al momento de aprobar un crédito. López (2015)

Las ventas a crédito en Colombia

Según la definición de ventas a crédito es el tipo de operación en el que el pago se realiza en el marco del mediano o largo plazo, luego de la adquisición del bien 0 servicio. Se le llama venta a crédito a la que tiene el propósito de distribuir el pago del bien o servicio adquirido en un determinado plazo pautado de antemano entre el comprador y el vendedor, de manera que el primero pueda amortizarlo, por ejemplo, en varios meses. Definición ABC. (2017)

Muchas empresas tienen como único objetivo crecer mediante el aumento continuado de su facturación y para ello ofrecen crédito comercial a sus clientes y amplias facilidades de pago. León (2017), así mismo la revista Dinero (2011), manifiesta que en mayor o menor medida, este fenómeno se repite en otras partes de América Latina, donde el auge del crédito privado en los últimos años ha sido uno de los motores claves del crecimiento económico.

Así mismo, las ventas a crédito es un fenómeno que ha venido creciendo en los últimos años en Colombia, menciona la revista Dinero (2017), Las líneas de mercancía 
que más aportaron al alza en las ventas del comercio minorista, durante junio, fueron los víveres en general y las bebidas no alcohólicas pues tuvieron una variación anual de $5,2 \%$. Por su parte, los electrodomésticos, muebles para el hogar y equipo de informática y telecomunicaciones para uso personal o doméstico con $5,8 \%$, y otras mercancías para uso personal 0 doméstico, no especificadas anteriormente con $8,0 \%$.

Continuando con el tema, sacar un crédito personal en una casa de electrodomésticos es hasta tres veces más caro que a través de un banco. Esto se da porque, mientras en las principales cadenas de artículos para el hogar se cobra una tasa de interés nominal anual de hasta $125 \%$ (que depende principalmente del plazo de otorgamiento del préstamo), en las entidades financieras tiene un costo total que oscila entre $30 \%$ y $40 \%$. Según el Ámbito Financiero (2007), los establecimientos comerciales ofrecen gran variedad de posibilidades para financiar las ventas especialmente de electrodomésticos a clientes no bancarizados, quienes no pueden acceder a préstamos personales, estos créditos están dirigidos a sectores de bajos recursos los cuales están dispuestos a pagar la tasa que le sea cobrada por tener acceso a otra posibilidad crediticia.

\section{METODOLOGÍA:}

Se realizó un estudio descriptivo con un enfoque cuantitativo, con el propósito de analizar las ventas a crédito del Municipio de Pamplona y el tipo de interés cobrado por los comerciantes. Según Hernández, (2015) la investigación descriptiva busca especificar propiedades, características y rasgos importantes de cualquier fenómeno que se analice. Describe tendencias de un grupo 0 poblaciòn. Para ello se tomó como referencia las empresas comerciales dedicadas a vender a crédito específicamente de los sectores muebles y electrodomésticos, para analizar qué tasa de interés es la que debe pagar el usuario, esta muestra correspondió al $60 \%$ del total de las empresas formalmente registradas en Cámara de Comercio. El proceso metodológico se ejecutó mediante dos fases: Fase 1. Se realizó una cotización para comprar a crédito de un determinado artículo, donde se solicitaba el precio al contado y el precio si se comprara a crédito dando una cuota inicial, el valor de la cuota y número de cuotas a pagar. Fase 2. Con base en la información suministrada por cada uno de los almacenes cotizados se procedió a determinar la tasa de interés efectivo periódico nominal anual y la tasa de interés efectiva anual, para determinar si la tasa de interés cobrada está por debajo o por encima de la tasa permitida por la ley más conocida como la tasa de usura. Como las ventas a crédito de este trabajo son bajo la modalidad de cuotas iguales en matemáticas financieras se conoce como Anualidades.

Para calcular la tasa de interés en las anualidades no hay una fórmula, matemática específica, pero se puede calcular a través de tres formas: Utilizando el Excel, Utilizando las calculadoras financieras, Interpolando. Para el cálculo de las tasas de interés esta investigación se utilizó el Excel ya que es una herramienta que en fracciones de segundo calcula dichas tasas. Así mismo para entrar a determinar la tasa se realizó el proceso de hallar el porcentaje para la cotización número 1 , a través del Excel paso por paso como se describe a continuación:

El proceso de cotización fue planeado para vincular en las respuestas la información requerida para el cumplimiento de los objetivos del estudio. El ejercicio de la primera cotización para compra de un electrodoméstico, se ejemplifica en la Tabla 1.

Tabla 1. Datos de la cotización realizada.

\begin{tabular}{|l|l|l|l|l|}
\hline $\begin{array}{l}\text { Precio } \\
\text { de } \\
\text { contado }\end{array}$ & $\begin{array}{l}\text { Cuota } \\
\text { inicial }\end{array}$ & $\begin{array}{l}\text { Valor a } \\
\text { Financiar }\end{array}$ & $\begin{array}{l}\text { Número } \\
\text { de } \\
\text { cuotas }\end{array}$ & $\begin{array}{l}\text { Valor } \\
\text { de la } \\
\text { cuota }\end{array}$ \\
\hline 500.000 & 100.000 & 400.000 & 12 & 38.200 \\
\hline
\end{tabular}

Fuente: los autores, (2016)

Para el desarrollo analítico de la fase 2. Se procedió a hallar: Interés mensual, Interés nominal anual, y el Interés efectivo anual. Por consiguiente se muestra el resultado de las 12 cotizaciones después de calcular sus respectivas tasas, arrojando los siguientes resultados, como lo muestra la Tabla 2.

Tabla 2. Cálculo de las diferentes tasa de interés.

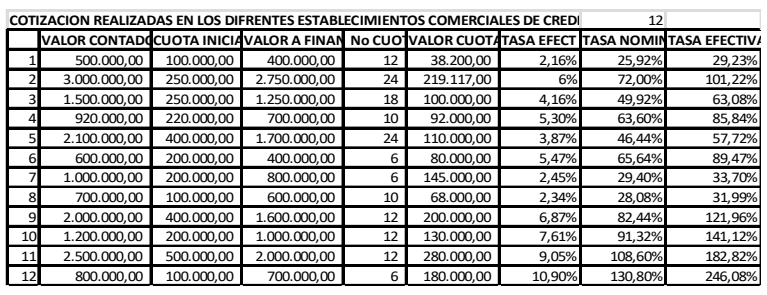

Fuente los autores, (2016)

\section{ANALISIS DE RESULTADOS:}

Al analizar la información arrojada de las 12 cotizaciones realizadas en los establecimientos comerciales del municipio de Pamplona, se pudo concluir:

-El primer almacén está cobrando una tasa de financiación del $2,16 \%$ mensual equivalente a una tasa nominal del 
$25.92 \%$ nominal anual y equivalente a una tasa efectiva anual del $29.23 \%$. Como se puede observar en los pantallazos de Excel. La cual está por debajo de la tasa de usura permitida por la Ley.

-En las demás cotizaciones también se realizó el cálculo como se muestra en la Tabla 2 y la tasas de interés mensual están entre el $2.34 \%$ mensual y el $10.90 \%$ mensual, tasa que están por encima de la tasa permitida por la ley o de la tasa de usura. (2.18 mensual)

Con lo anterior se puedo analizar que sólo el $8 \%$ de los establecimientos de comercio cumplen con los requerimientos exigidos por la ley para otorgar créditos de financiación comercial y el $92 \%$ de los establecimientos de comercio cobran tasa por encima de la tasa de usura, perjudicando económicamente al consumidor final.

Grafico 2. Establecimientos que cobran las tasa de interés de acuerdo a la ley.

Fuente los autores, (2016)

-El $8 \%$ de las empresas está por debajo de la tasa permitida por la ley, el $58 \%$ está entre la tasa permitida por la ley, y un $4 \%$ mensual cabe anotar que están por encima de la tasa de usura, y el $30 \%$ está por encima de $6 \%$ mensual, tasa que son elevadas; también por encima de la tasa de usura.

\section{CONCLUSION:}

- Realizado el estudio fue posible analizar y llegar a evidenciar que la mayoría de las empresas comerciales del municipio de Pamplona dedicadas a vender a crédito muebles y electrodomésticos cobran el interés más a arriba de la tasa de interés permitida teniendo en cuenta que la tasa de usura es del $2.18 \%$ mensual.

-Encontrando coherencia por lo planteado por el diario Portafolio (2007), cuando menciona, que la compra de televisores, neveras o computadores se mantiene disparada, a través del crédito. Y aunque el aumento de las tasas de interés lo ha frenado un poco no es del todo una dificultad para las familias sobre todo de estratos bajos, quien ven en esta forma de ventas a crédito una manera fácil de adquirir los bienes para el hogar, sin importar la tasa de interés cobrado.

-Debido a este fenómeno donde ha crecido el endeudamiento, es necesario crear conciencia en los lectores de esta artículo de la importancia de analizar la tasa de interés que están cobrando los almacenes a la hora de efectuar una compra a crédito, ya que al momento de realizar la compra nunca le manifiestan al cliente cuál es la tasa con la que le están financiando el crédito, de acuerdo a lo comprobado con en este estudio.
-Se debe analizar varias alternativas antes de comprar si comprar un artículo dando una cuota inicial y pagando el resto a crédito, comprar de contado o pagar con la tarjeta de crédito, o hacer un crédito en una entidad financiera. Cuando la tasa es muy elevada es preferible usar la tarjeta de crédito, ya que estas cobran casi sobre la tasa permitida por la ley, teniendo como consecuencia que si la saca al mismo número de cuotas el valor de la cuota le disminuye considerablemente afectando positivamente los gastos familiares. Finalmente para concluir es importante entender que hay diferentes maneras de realizar un crédito comercial, que utilizado inteligentemente puede ser una buena alternativa para adquirir un bien.

\section{REFERENCIAS:}

Actualícese (2011). Compra a crédito directamente con el vendedor. Cobro de intereses de plazo y mora, disponible

en: http://actualicese.com/actualidad/2011/11/03/com pra-a-credito-directamente-con-el-vendedorcobro-de-intereses-de-plazo-y-mora/, Consultada [10 de junio de 2017]

Álvarez. (2005). Matemáticas Financieras, tercera edición, año, editorial McGraw-Hill

Ámbito Financiero (2007). El reino de la Usura. Disponible en: http://www.ambito.com/350222-el-reino-de-lausura. Consultada [10 de junio de 2017]

Asobancaria, (2015). Crédito informal, Disponible en: http://www.asobancaria.com/sabermassermas/cr edito-informal/

Banco de la República (2016). la tasa de Usura. Disponible en:

http://www.banrepcultural.org/blaavirtual/ayudade tareas/economia/usura. Consultada [10 de junio de 2017]

Banco de la república, la tasa de interés. (2013). Disponible en: http://www.banrep.gov.co/es/tasas-interes, [Consultada 10 de junio de 2017]

Breviarios. (2017). Historia de la usura, disponible en: mibug.wordpress.com/2008/10/12/historia-de-lausura/. Consultada [10 de junio de 2017]

Definición ABC, (2017), Ventas a Credito. Disponible en: 
https://www.definicionabc.com/economia/venta-acredito.php. Consultada [10 de junio de 2017]

Enciclopedia de Economía (2009). Disponible en: http://www.economia48.com/spa/d/credito/credito .htm. Consultada [10 de junio de 2017]

Hernández Sampieri. (2015). Metodología de la investigación, quinta edición. Editorial Mac Graw Hill.

Historia de la usura. (2008) La aldea, Banca y comercio, argentina. Disponible en: http://www.taringa.net/posts/info/1646435/Historia -De-La-Usura.html. Consultada [10 de junio de 2017]

Meza. (2008). Matemáticas Financieras aplicadas, tercera edición año, editorial Eco ediciones.

Montes (2010). Crédito y comercio internacional, pilares del desarrollo en el mundo, disponible en:http://www.revistasice.com/CachePDF/ICE_85 3_5

24 _ 04D48EC2885CADA51E27703D5F854233. pdf Consultada [9 de junio de 2017]

Palermo, (2016). Como vivir sin aburrirse, Claves para una vida con sentido. Disponible en: /books.google.com.co/books? $\mathrm{id}=2$ FdJDQAAQBAJ\&pg=PT52\&lpg=PT52\&dq=el +dinero+y+su+dificultad+para+conseguirlo\&sourc e=bl\&ots=pcdNpgBSCR\&sig=v-

Kx9nvLYmhanVb0LB4BQ_dfGBI\&hl=es\&sa=X\&v ed=0ahUKEwia4aefosvVAhVGSyYKHUyMA0oQ

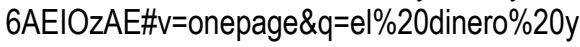
$\% 20$ su\%20dificultad\%20para $\% 20$ conseguirlo\&f=false. Consultada [10 de junio de 2017]

Portafolio (2008). Bienes de consumo: ¿inversión u oportunidad?. disponible en: http://www.portafolio.co/economia/finanzas/biene s-consumo-inversion-u- oportunidad-371876. Consultada [10 de junio de 2017]

Portafolio (2007). Bienes de consumo: ¿inversión u oportunidad?, disponible en: http://www.portafolio.co/economia/finanzas/biene s-consumo-inversion-u-oportunidad-371876, Consultada [12 de junio de 2017]
León Casso (2017). Ventas a credito sin control. Disponible en: http://elmanana.com.mx/opinion/140730. Consultada [12 de junio de 2017]

López Patiño (2015). El dilema de los créditos formales e informales en Colombia, Diario la república, Disponible en:

Catalina/www.larepublica.co/finanzas/el-dilema-de-loscreditos-formales-e-informales-en-colombia2218771. Consultada [12 de junio de 2017]

Rating Empresarial (2011). ventajas de la venta a credito, Disponible en: http://www.ratingempresarial.com/ventajas-de-laventa-a-credito/. Consultada [10 de junio de 2017]

Reina et at (2006). El dinero y la política monetaria, Edición del Banco de la Republica, disponible en: http://www.banrep.gov.co/docum/Lectura_finanza s/pdf/guia2_el_dinero_y_la_politica_monetaria.pd f. Consultada [10 de junio de 2017]

Revista Dinero (2011). Los riesgos del credito Bancario en América Latina, Disponible en: http://www.dinero.com/negocios/articulo/losriesgos-del-credito-barato-america-latina/136734. Consultada [10 de junio de 2017]

Revista Dinero (2017), Ventas minoristas subieron en junio impulsadas por alimentos y bebidas no alcohólicas, Disponible en: http://www.dinero.com/negocios/articulo/losriesgos-del-credito-barato-america-latina/136734. . Consultada [12 de junio de 2017]

Saint-hilaire,(2010). Teorías de la tasa de interes, Disponible:

http://santiler.tripod.com/econociencia/id10.html. Consultada [10 de junio de 2017]

Santacruz, (2013), Definición: ¿Qué es el Tipo de Interés Nominal?

Disponible en:www.oroyfinanzas.com/2013/04/definicionque-tipo-interes-nominal/. Consultada $[10$ de junio de 2017]

Soto Ibáñez, (2009). Financiera rural, influencia en dispersoras e intermediarios financieros rurales, zona centro del estado de Veracruz, Disponible en:

http://www.eumed.net/tesisdoctorales/2009/mcsi/ Teoria\%20del\%20Dinero\%20y\%20el $\% 20$ Credito.htm. Consultada [10 de junio de 2017] 
ISSN: 1794-9920 Enero - Abril de 2017

Volumen 17 Número 2, Año 2017 Págs. 120 - 129

Superfinanciera (2016). Tasa de usura primer trimestre del año 2016, Disponible en: https://www.superfinanciera.gov.co/jsp/loader.jsf? IServicio=Publicaciones\&ITipo=publicacione.

Consultada [10 de junio de 2017].

Subgerencia Cultural del Banco de la República. (2015). Crédito y amortizaciones. Disponible en: http://www.banrepcultural.org/blaavirtual/ayudade tareas/comunicacion/libro. Consultada [10 de junio de 2017]

Vargas, (2008). La inflación, disponible en: http://ecovictorlainflacion.blogspot.com.co/. Consultada [12 de junio de 2017] 